\title{
Simulations of large winds and wind shears induced by gravity wave breaking in the mesosphere and lower thermosphere (MLT) region
}

\author{
X. Liu ${ }^{1,2}$, J. Xu' ${ }^{1}$, H.-L. Liu ${ }^{3}$, J. Yue ${ }^{4}$, and W. Yuan ${ }^{1}$ \\ ${ }^{1}$ State Key Laboratory of Space Weather, Center for Space Science and Applied Research, Chinese Academy of Sciences, \\ Beijing 100190, China \\ ${ }^{2}$ College of Mathematics and Information Science, Henan Normal University, Xinxiang 453007, China \\ ${ }^{3}$ High Altitude Observatory, National Center for Atmospheric Research, Boulder, CO 80307, USA \\ ${ }^{4}$ Atmospheric and Planetary Sciences, Hampton University, Hampton, VA 23668, USA \\ Correspondence to: X. Liu (xliu@spaceweather.ac.cn)
}

Received: 17 February 2014 - Revised: 14 April 2014 - Accepted: 15 April 2014 - Published: 23 May 2014

\begin{abstract}
Using a fully nonlinear two-dimensional (2-D) numerical model, we simulated gravity waves (GWs) breaking and their contributions to the formation of large winds and wind shears in the mesosphere and lower thermosphere (MLT). An eddy diffusion coefficient is used in the 2-D numerical model to parameterize realistic turbulent mixing. Our study shows that the momentum deposited by breaking GWs accelerates the mean wind. The resultant large background wind increases the GW's apparent horizontal phase velocity and decreases the GW's intrinsic frequency and vertical wavelength. Both the accelerated mean wind and the decreased GW vertical wavelength contribute to the enhancement of wind shears. This, in turn, creates a background condition that favors the occurrence of GW instability, breaking, and momentum deposition, as well as mean wind acceleration, which further enhances the wind shears. We find that GWs with longer vertical wavelengths and faster horizontal phase velocity can induce larger winds, but they may not necessarily induce larger wind shears. In addition, the background temperature can affect the time and height of GW breaking, thus causing accelerated mean winds and wind shears.
\end{abstract}

Keywords. Meteorology and atmospheric dynamics (mesoscale meteorology; middle atmosphere dynamics; turbulence)

\section{Introduction}

Knowledge of wind structures in the mesosphere and lower thermosphere (MLT) has advanced in recent years with sounding rocket measurements and radar and lidar remotesensing techniques. In the chemical release experiment by sounding rockets at different latitudes, longitudes, seasons, and local times, large horizontal winds and strong vertical shears have been measured (e.g., Wu and Widdel, 1992; Larsen, 2000, 2002; Larsen et al., 2005; Larsen and Fesen, 2009; Koizumi et al., 2009). Moreover, both the magnitudes and vertical structures of winds and shears measured by the sodium lidar and non-specular meteor radar are in line with those obtained by sounding rocket measurements (e.g., Larsen et al., 2003, 2004; She, 2004; Larsen and Fesen, 2009; Oppenheim et al., 2009, 2014; Yue et al., 2010). Various wind measurement techniques indicated that large winds and wind shears occur frequently in the MLT region regardless of local times, seasons, latitudes, and longitudes (Larsen, 2002).

Large winds and wind shears in the MLT region play important roles in dynamical, electrodynamical, chemical, and transport processes. For example, large wind shears affect the stability and dissipation of GWs (Fritts and Alexander, 2003). Large wind shears can lead to the formation of sporadic E and sporadic sodium layers (Whitehead, 1970; Clemesha, 1995; Qian et al., 1998; Miyagawa et al., 1999; Larsen et al., 2005). Large wind shears provide favorable conditions for producing Kelvin-Helmholtz (KH) instability, which can perturb airglow emissions (Hecht, 2004; Snively et al., 2007; Liu et al., 2009). Large winds also play an 
important role in the transport of constituents both in the zonal and meridional directions (Liu, 2007; Yue and Liu, 2010; Yue et al., 2013).

However, ground-measured large winds and wind shears are often absent from wind climatologies derived from satellites; they are also underestimated in the empirical Horizontal Wind Model (HWM) model and the general circulation model (e.g., NCAR TIME-GCM: National Center for Atmospheric Research, Thermosphere Ionosphere Mesosphere Electrodynamics-General Circulation Model). Possible mechanisms for the formation of large winds and wind shears have been proposed (Zhao et al., 2003; Fritts et al., 2004; Li et al., 2005, 2009; Liu, 2007; Larsen and Fesen, 2009; Yue et al., 2010). Various waves, including GWS, tides and planetary waves, are possible contributors to the formation of large winds and wind shears. Liu (2007) found that the theoretical maximum shears allowed by the background temperature and dynamical stability are similar to those obtained by sounding rocket measurements. However, these large shears cannot be reproduced in global models because the waves are either unresolvable (e.g., GWs) or underestimated (e.g., tides) due to coarse model resolutions (Larsen and Fesen, 2009). Strong GW activities and the resultant turbulence can contribute to the formation of large winds and wind shears (Fritts et al., 2004). But subgrid-scale GWs are often parameterized in GCMs. A recent study by Yue et al. (2010) found that the semidiurnal tides significantly contribute to the large shears in the MLT at mid-latitudes.

Above the mesopause region, the positive temperature gradient and strong static stability can support larger amplitude GWs (VanZandt and Fritts, 1989; Liu, 2007). When these larger amplitude GWs become unstable, they deposit more momentum and energy, induce larger mean winds and wind shears, and decrease the positive temperature gradient (Fritts et al., 2004). This, in turn, provides a favorable condition for inducing more GW instability and breaking, along with momentum deposition and mean wind acceleration. Thus, a positive feedback process is formed among GW instability and breaking, momentum deposition, mean flow acceleration, decreased GW vertical wavelength, and enhanced wind shear.

This positive feedback process is difficult to quantify in a global model because resolved GWs are absent. In this work, the process of large winds and wind shears formation will be investigated in more detail using a nonlinear twodimensional (2-D) GW numerical model (Liu et al., 2008, 2009 , 2013). Although a 2-D GW model is very computationally efficient, its main deficiency is simulated unrealistically long overturning time, leading to wave amplitudes that are too large (Fritts et al., 1996, 1998, 2009a, b; Andreassen et al., 1998). The enhanced mixing of streamwise-aligned (parallel to the wave propagation direction) vortices caused by GW breaking in three-dimensional (3-D) models cannot be resolved because the 2-D models do not have a horizontal dimension perpendicular to the wave propagation direction (Andreassen et al., 1994; Fritts et al., 1994, 1996).
Andreassen et al. (1994) suggested that if the enhanced mixing effect in a 3-D model is parameterized properly in a 2-D model, the 2-D model could emulate the effect of 3-D instability on GW breaking and mean wind acceleration. By introducing a turbulence transport model into a 2-D GW model, Liu et al. (1999) demonstrated that general features of wavemean-flow interaction could be well represented.

In this 2-D model, we use a turbulence model to parameterize the effects of 3-D mixing on the mean flow. A costeffective and commonly used turbulence closure model is eddy diffusion formulation with a "switch-on" eddy diffusion coefficient when the local Richardson number $(R i)$ drops below the critical value of dynamic instability $(R i \leq 1 / 4)$ (Liu et al., 1999). An eddy diffusion coefficient was carefully selected to study the GW breaking and the formation of large winds and wind shears in the MLT region.

The 2-D numerical model and its initial configurations are described in Sect. 2. In Sect. 3, we present a case that shows the propagation and breaking of GWs and the formation of large winds and wind shears. In Sect. 4, comparative studies are performed to examine the effects of $\mathrm{GW}$ wavelengths and background temperatures on the formation of large winds and wind shears. Our conclusions are given in Sect. 5.

\section{Numerical model}

The 2-D numerical model was initially developed by Liu et al. (2008) and has been used to study the nonlinear interactions between tides and GWs and the resultant transient variations of tidal amplitudes. The numerical model was also used to study the nonlinear propagation of GWs from the lower atmosphere into the MLT region and the formation of Kelvin-Helmholtz billows (Liu et al., 2009). Recently, both molecular and eddy diffusions were introduced into the model to study their effects on the momentum deposition of small-amplitude and non-breaking GWs in the lower thermosphere (Liu et al., 2013). The governing equations are the two-dimensional compressible, nonlinear Navier-Stokes equations and the equation of state for an ideal gas:

$$
\begin{aligned}
\frac{\partial \rho}{\partial t}+\rho \nabla \cdot \boldsymbol{U}=0, & \\
\frac{D \boldsymbol{U}}{D t}+\frac{1}{\rho} \nabla p-\boldsymbol{g} & =\frac{1}{\rho} \nabla \cdot\left(\rho K_{\mathrm{diss}} \nabla \boldsymbol{U}\right) \\
& +\frac{1}{3 \rho} \nabla\left(\rho K_{\mathrm{diss}} \nabla \cdot \boldsymbol{U}\right)-\alpha(z) \boldsymbol{U}^{\prime},
\end{aligned}
$$

$$
\frac{D T}{D t}+\frac{R T}{c_{\mathrm{v}}}(\nabla \cdot \boldsymbol{U})=\frac{\gamma}{\rho} \nabla \cdot\left(\rho K_{\mathrm{diss}} \nabla T\right)-\alpha(z) T^{\prime}+\Phi,
$$

$$
p=\rho R T \text {. }
$$


$\boldsymbol{U}=(u, w), \quad \boldsymbol{U}^{\prime}=\left(u^{\prime}, w^{\prime}\right), \quad \nabla=\left(\frac{\partial}{\partial x}, \frac{\partial}{\partial z}\right)$,

$\frac{D}{D t}=\frac{\partial}{\partial t}+\boldsymbol{U} \cdot \nabla, \quad \boldsymbol{g}=(0,-g)$,

$\Phi=\frac{2 K_{\mathrm{diss}}}{c_{v}}\left[e_{i j} e_{i j}-\frac{1}{3}(\nabla \cdot \boldsymbol{U})^{2}\right], \quad e_{x x}=\frac{\partial u}{\partial x}$,

$e_{z z}=\frac{\partial w}{\partial z}, \quad e_{x z}=e_{z x}=\frac{1}{2}\left(\frac{\partial u}{\partial z}+\frac{\partial w}{\partial x}\right)$,

where $x$ and $z$ are the horizontal and vertical coordinates; $g$ is the acceleration of gravity; $\rho, p$ and $T$ are the density, pressure, and temperature, respectively, of atmosphere; $u$ and $w$ are the horizontal and vertical velocities, respectively; $c_{\mathrm{V}}$ is the specific heat at constant volume; $\gamma$ is the ratio of specific heat; and $R$ is the gas constant for dry air. In the equations, $u^{\prime}, w^{\prime}$ and $T^{\prime}$ are the time-dependent fluctuations associated with the GWs, and they are calculated by subtracting the average values over the horizontal domain from the total values (Xu et al., 2003). The Rayleigh friction $\alpha(z)$ is adapted from $\mathrm{Xu}$ et al. (2003) to reduce or eliminate spurious reflection from the lower and upper boundaries.

The initial GW packet launched in the 2-D model has the same spatial shape as that in Liu et al. (2013):

$$
\begin{gathered}
u^{\prime}(x, z, t=0)=A \exp \left[-\ln (2) \times \frac{\left(z-z_{0}\right)^{2}}{2 \sigma_{z}^{2}}\right] \\
\exp \left(\frac{z-z_{0}}{2 H}\right) \cos \left[k_{x} x+k_{z}\left(z-z_{0}\right)\right] .
\end{gathered}
$$

The horizontal and vertical wave numbers are $k_{x}=2 \pi / \lambda_{x}$ and $k_{z}=-2 \pi / \lambda_{z} ; \lambda_{x}$ and $\lambda_{z}$ are the horizontal and vertical wavelengths, respectively. The center of the initial wave packet is located at the altitude of $z_{0}=45 \mathrm{~km}$. The observations showed that the typical horizontal wavelengths of the dominant GWs in the MLT region vary from several tens to several thousands of kilometers, and the vertical wavelengths are usually $4-15 \mathrm{~km}$ and can be as large as ca. $30 \mathrm{~km}$ (e.g., Manson and Meek, 1988; Nakamura et al., 1993; Fritts and Alexander, 2003; Hu et al., 2002; Kubota et al., 2006; $\mathrm{Lu}$ et al., 2009). Based on these observations, three different wave packages are launched individually in different runs: a large-scale $\mathrm{GW}$ (L: $\lambda_{x}=400 \mathrm{~km}, \lambda_{z}=20 \mathrm{~km}$, period $\left.\left(\tau_{\mathrm{gW}}\right)=112 \mathrm{~min}\right)$, a medium-scale $\mathrm{GW}\left(\mathrm{M}: \lambda_{x}=200 \mathrm{~km}\right.$, $\left.\lambda_{z}=15 \mathrm{~km}, \tau_{\mathrm{gw}}=74 \mathrm{~min}\right)$, and a small-scale $\mathrm{GW}\left(\mathrm{S}: \lambda_{x}=\right.$ $\left.100 \mathrm{~km}, \lambda_{z}=10 \mathrm{~km}, \tau_{\mathrm{gw}}=55 \mathrm{~min}\right)$.

The wave amplitude is $A=2.5 \mathrm{~m} \mathrm{~s}^{-1}$ to ensure that wave overturning and breaking occur in the MLT region. The wave amplitude chosen here results in the peak momentum flux of $1.5 \times 10^{-3} \mathrm{~Pa}, 1.1 \times 10^{-3} \mathrm{~Pa}$, and $0.7 \times 10^{-3} \mathrm{~Pa}$, which are consistent with the climatological value of $\sim 1-5 \times 10^{-3} \mathrm{~Pa}$ in the stratosphere (Fritts and Alexander, 2003). To properly simulate the overturning and breaking of GWs, our simulations are performed in the computational domain with uniform grid spaces of $\lambda_{x} / 200 \mathrm{~km}$ and $0.05 \mathrm{~km}$ in the horizontal and vertical directions, respectively.

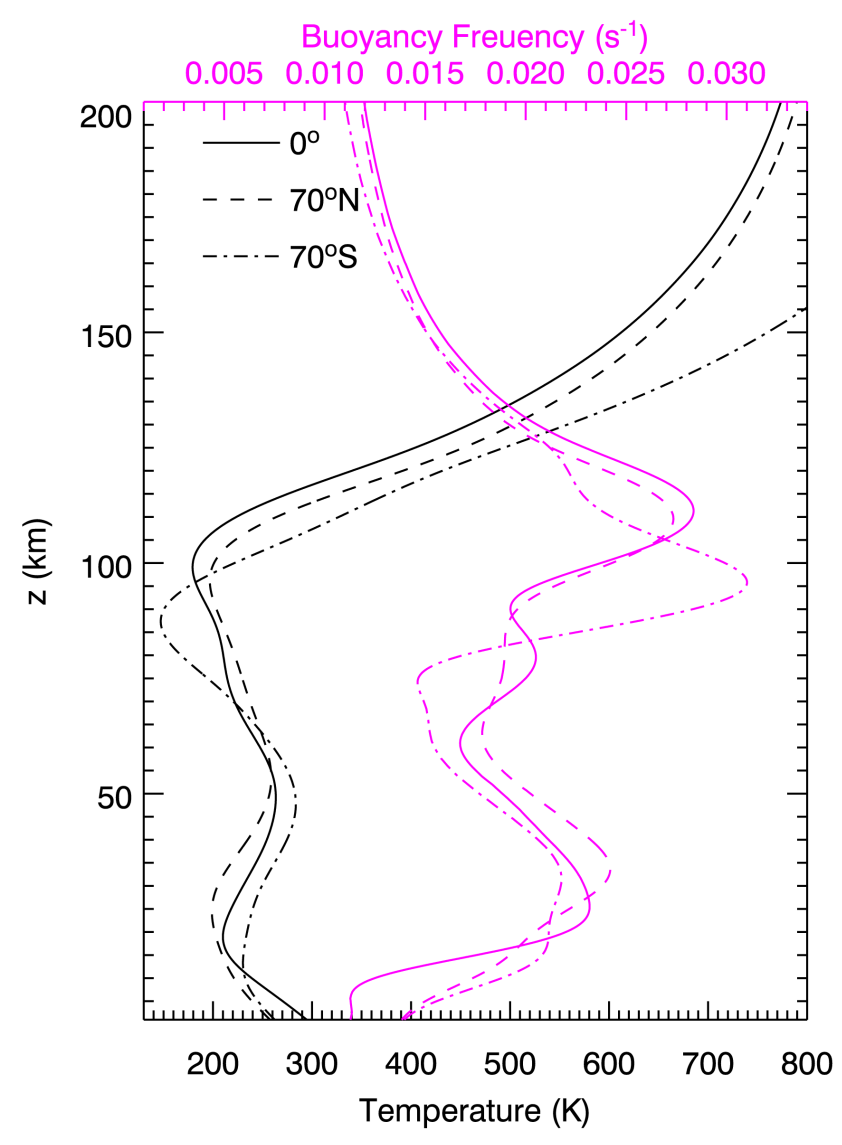

Figure 1. Temperature profiles (the black lines, the bottom $x$ axis) calculated from NRLMSIS-00 at three latitudes $\left(0^{\circ}\right.$ : the solid line, $70^{\circ} \mathrm{N}$ : the dash line, $70^{\circ} \mathrm{S}$ : the dash dot line) on day 355 and the corresponding buoyancy frequency (the red lines, the upper $x$ axis).

The background temperature profiles from NRLMSIS-00 (Picone et al., 2002) at three latitudes $\left(70^{\circ} \mathrm{S}, 0^{\circ}, 70^{\circ} \mathrm{N}\right)$ on the 355th day of the year are selected for our numerical experiments (Fig. 1). The profiles of buoyancy frequency $N$ calculated from the corresponding temperature profiles are also shown in Fig. 1. These temperature profiles are chosen to represent the seasonal and latitudinal variations of the background atmosphere. The initial background winds are set to zero both in the horizontal and vertical directions so that their filtering effects on GWs can be neglected. We focus on the effects of the initial background temperature and GW scales on the formation of large winds and wind shears in the MLT region. The effect of the interaction between background (mean and tidal) wind field and GWs is a subject of our future work.

According to the initial background temperature at the latitudes of Equator $(\mathrm{E}), 70^{\circ} \mathrm{N}(\mathrm{N}), 70^{\circ} \mathrm{S}(\mathrm{S})$, and different wave scales, the numerical experiments are denoted as $[\mathrm{E} / \mathrm{N} / \mathrm{S}][\mathrm{L} / \mathrm{M} / \mathrm{S}]$.

The diffusion coefficient $K_{\text {diss }}$ is the sum of the molecular $(v)$ and eddy $(\eta)$ diffusions. Here, the standard molecular 
diffusion is adopted from Banks and Kockarts (1973) and written as (unit is $\mathrm{m}^{2} \mathrm{~s}^{-1}$ )

$v(z)=3.5 \times 10^{-7} T(z)^{0.69} / \rho(z)$.

Since the atmospheric density $(\rho)$ decreases exponentially with height, the molecular diffusion increases exponentially with height and dissipates upward propagating GWs efficiently in the thermosphere (Vadas and Fritts, 2005; Liu et al., 2013).

For the eddy diffusion, its magnitude varies in the range of $10-1000 \mathrm{~m}^{2} \mathrm{~s}^{-1}$ in the MLT region, depending on seasons and latitudes (Hocking, 1987; Xu et al., 2009). The proper magnitude of eddy diffusion in the 2-D model is adjusted to obtain a realistic overturning time (Andreassen et al., 1994; Fritts et al., 1996; Lund and Fritts, 2012). We chose an observed value of $100 \mathrm{~m}^{2} \mathrm{~s}^{-1}$ (Keneshea et al., 1979; Hocking, 1987; Fukao et al., 1994), which produces a GW overturning time of $\sim 2.9$ times of $\tau_{\mathrm{gw}}$. This is close to previously reported values of $\sim 2.5$ times of $\tau_{\mathrm{gw}}$ from 3-D models (Andreassen et al., 1994; Lund and Fritts, 2012). Our numerical experiments also show that the increasing eddy diffusion reduces the overturning time and the magnitudes of winds and wind shears in the MLT region.

\section{Case study}

The time-height contours of the total wind (a), mean wind (b), perturbation wind (c) and total wind shear (d) located at the midpoint of the horizontal domain for the case EM are shown in Fig. 2. Here, the mean wind is calculated by averaging the total wind over the horizontal computational domain (equivalent to one horizontal wavelength). The perturbation wind is calculated by subtracting the mean wind from the total wind. Figure 2 shows that the maximum total wind is as large as $170 \mathrm{~m} \mathrm{~s}^{-1}$ at the time interval of 200$280 \mathrm{~min}$ (Fig. 2a) and that the maximum mean wind moves downward from the height of $\sim 120$ to $\sim 100 \mathrm{~km}$ (Fig. $2 \mathrm{~b}$ ). The downward movement of the maximum mean wind is mainly caused by the dispersion of a GW packet propagating through non-isothermal temperature background. GWs with fast vertical group velocity propagate upward quickly and deposit their momentum in the lower thermosphere. This induces the maximum mean wind above $115 \mathrm{~km}$. At a later time, GW propagation becomes slower, and most GWs break in the MLT region.

Figure 2 illustrates that the mean wind reaches $\sim 120 \mathrm{~m} \mathrm{~s}^{-1}$ at $230 \mathrm{~min}$ in the height range of $105-115 \mathrm{~km}$ (Fig. 2b). The maximum of the total wind shear at the same altitude is $\sim 82 \mathrm{~m} \mathrm{~s}^{-1} \mathrm{~km}^{-1}$. These winds and wind shears are consistent with those observed by rocket chemical release experiments in both the height range $(95-120 \mathrm{~km})$ and magnitude $\left(>100 \mathrm{~m} \mathrm{~s}^{-1}\right.$ in wind, $>40 \mathrm{~m} \mathrm{~s}^{-1} \mathrm{~km}^{-1}$ in wind shear; Larsen, 2002). Although the induced wind and wind shear magnitudes are dependent on the initial wave amplitudes and

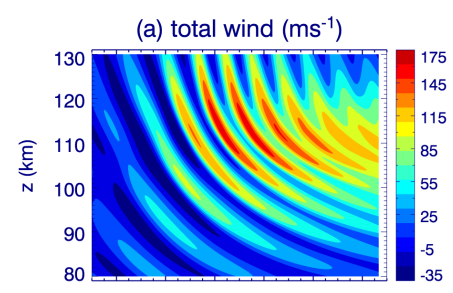

(c) perturbation wind $\left(\mathrm{ms}^{-1}\right)$

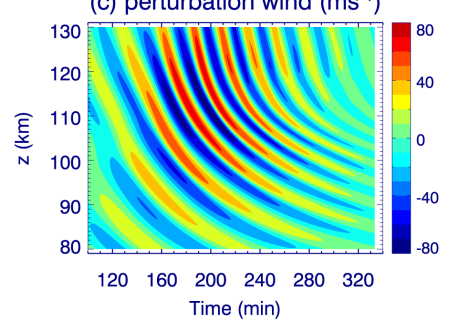

(b) mean wind $\left(\mathrm{ms}^{-1}\right)$

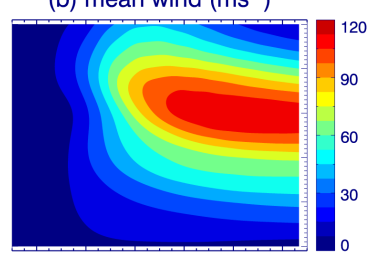

(d) total wind shear $\left(\mathrm{ms}^{-1} \mathrm{~km}^{-1}\right)$

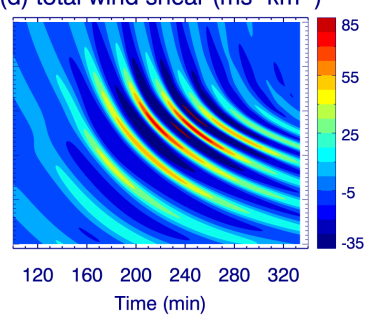

Figure 2. Time-height contours of the (a) total wind, (b) mean wind, (c) perturbation wind and (d) total wind shear located at the midpoint of the horizontal computation domain for the case EM (GW with $\lambda_{z}=15 \mathrm{~km}$ ).

scales, the numerical model results show that the momentum deposition that results from GW breaking always forms large winds and wind shears (Fritts et al., 2004). The enhanced eddy diffusion reduces the magnitude of total wind and wind shear, but it does not undermine the physical mechanism. Here the mechanism is that large winds and wind shears can be caused through GW breaking and mean flow interactions. The maximum total wind shear is $\sim 46 \mathrm{~m} \mathrm{~s}^{-1} \mathrm{~km}^{-1}$ if the eddy diffusion coefficient is raised to $300 \mathrm{~m}^{2} \mathrm{~s}^{-1}$ from $100 \mathrm{~m}^{2} \mathrm{~s}^{-1}$ in the model (not shown here). We note that Fig. 2a and c do not exhibit GW breaking features. Because the main purpose of this paper is to study the GW-meanflow interaction, the turbulence mixing is parameterized by an eddy diffusion coefficient. The evolution of the GW itself after the turbulence model is turned on should not be taken literally. By properly choosing eddy diffusion coefficient, the production of breaking GWs is suppressed by the dissipation of eddy and molecular diffusions. Thus, we cannot see the breaking signatures in Fig. 2. If we turn off the eddy diffusion in the 2-D model, wave breaking can be simulated but with unrealistic long overturning time (not shown).

As mentioned earlier, the maximum mean wind reaches a value of $\sim 120 \mathrm{~m} \mathrm{~s}^{-1}$ at the height of $\sim 110 \mathrm{~km}$ and at $\sim 230$ min, as shown in Fig. 2b. This is much faster than the apparent (relative to the observer on the ground) horizontal phase velocity of $45.1 \mathrm{~m} \mathrm{~s}^{-1}$ of the initial GW at $45 \mathrm{~km}$. To clarify this contradiction, we plot the temporal evolution of the mean wind ( $\bar{u}$, the red dash line), the apparent horizontal phase velocity ( $c_{p x}$, the red solid line), and the apparent wave period ( $\tau_{\mathrm{gw}}$, the black solid line), as well as the amplitude of perturbation wind $\left(\max \left(u^{\prime}\right)\right.$, the red dash dot line) and the intrinsic (relative to the observer moving with mean wind) horizontal phase velocity $\left(c_{p x}-\bar{u}\right.$, the red dot line) at 
$z=110 \mathrm{~km}$ (Fig. 3). Here, $\tau_{\mathrm{gw}}$ is calculated from the time series of perturbation wind $u^{\prime}$ at $z=110 \mathrm{~km}$ with the method of discrete Fourier transformation (DFT) confined in a sliding window. Then $c_{p x}$ is calculated from $\lambda_{x} / \tau_{\mathrm{gw}}$. From Fig. 3, we can see that the increasing mean wind drives the apparent phase velocity $c_{p x}$ to a magnitude $\sim 130-150 \mathrm{~m} \mathrm{~s}^{-1}$. This is probably caused by the self-acceleration of GWs due to the strong mean wind. The self-acceleration results in the increase of $c_{p x}$ and has been simulated by Fritts and Dunkerton (1984) who used a quasi-linear numerical model, and by Walterscheid and Schubert (1990), Liu et al. (1999) and Fritts and Lund (2011) using nonlinear numerical models. However, the physical process of the self-acceleration is still unclear. The increasing $c_{p x}$ decreases $\tau_{\mathrm{gw}}\left(=\lambda_{x} / c_{p x}\right)$ and increases the apparent GW frequency under a periodical horizontal boundary condition.

Figure 3 also illustrates that the amplitude of horizontal velocity perturbation (the red dash dot line) exceeds the GW intrinsic phase velocity (the red dot line) since $188 \mathrm{~min}$. This shows the occurrence of super-saturation. The degree of super-saturation $(\alpha)$ is defined as the ratio between the GW horizontal velocity perturbation amplitude and GW intrinsic phase velocity (Weinstock, 1988). The maximum degree of the super-saturation is about 2 between 200 and $240 \mathrm{~min}$ and is consistent with $\alpha$ and varies from 1.25 to 3.0 in Weinstock (1987). This value is also consistent with the in situ experimental result of $\alpha=2.8$ presented by Philbrick et al. (1984) and reanalyzed by Weinstock (1988). The maximum degree of super-saturation reported here is also supported by a recent 3-D model in which $\alpha=1.6$ (Lund and Fritts, 2012). Super-saturation is possibly a nonlinear effect, but was also present in quasi-linear models (Fritts and Dunkerton, 1984). Due to super-saturation and stronger wind perturbation, the maximum shear can be larger than that expected based on the linear saturation theory.

The wind shear is determined not only by the wind amplitude, but also by the vertical wavelength of GW. Figure 4 shows the temporal variations of the vertical wavelength $\left(\lambda_{z}\right)$ of dominant GWs, which is calculated by applying DFT on the profiles of horizontal velocity perturbation. These profiles located at the midpoint of the horizontal computation domain and in the height range of $80-140 \mathrm{~km}$, with the center at $110 \mathrm{~km}$. It can be seen that $\lambda_{z}$ increases first from the initial 15 to $20 \mathrm{~km}(\sim 1.33$ times the initial vertical wavelength) at $150 \mathrm{~min}$ and then decreases with time after $160 \mathrm{~min}$. To explain the variations of $\lambda_{z}$, a simplified dispersion relation is invoked (Fritts and Alexander, 2003):

$\lambda_{z}=\lambda_{x} \Omega / N$.

Here, $\Omega$ is the GW's intrinsic frequency (relative to the observer moving with mean wind); $N$ is the background buoyancy frequency (the red solid line in Fig. 1). Equation (7) indicates that a larger $N$ or smaller $\Omega$ leads to a shorter vertical wavelength given constant $\lambda_{x}$ in our model. Thus, at $150 \mathrm{~min}$ and $110 \mathrm{~km}$, the apparent period changed from 74

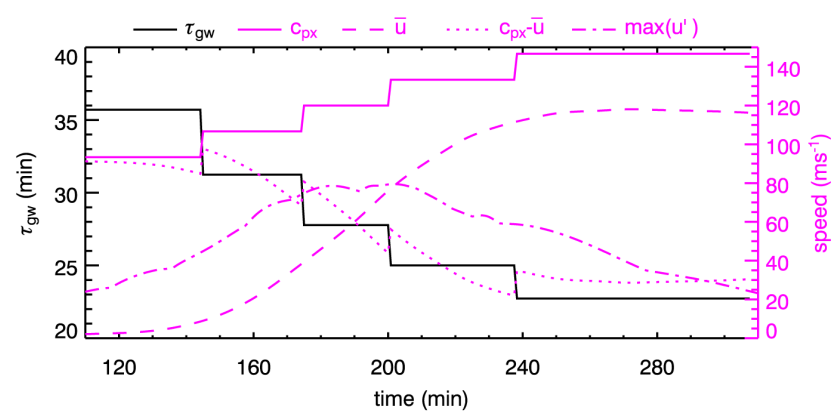

Figure 3. Temporal evolution of GW period ( $\tau_{\mathrm{gw}}$, left axis, the black solid line), mean wind ( $\bar{u}$, right axis, the red dash line), the apparent horizontal phase velocity ( $c_{p x}$, right axis, the red solid line), the amplitude of perturbation wind $\left(\max \left(u^{\prime}\right)\right.$, right axis, the red dash-dot line) and the intrinsic horizontal phase velocity $\left(c_{p x}-\bar{u}\right.$, right axis, the red dot line) for the case EM at $110 \mathrm{~km}$.

to about $32 \mathrm{~min}$ (Fig. 3). At this time, the apparent wave period equals the intrinsic wave period because of the negligible mean wind. Thus, the intrinsic frequency increases 2.3 ( 74/32 min) times. After considering that $N$ increased $\sim 1.6$ times from $\sim 45$ to $\sim 110 \mathrm{~km}$ (the red solid line in Fig. 1), according Eq. (7), the vertical wavelength at $150 \mathrm{~min}$ is about $21.5 \mathrm{~km}(\sim(2.3 / 1.6) \times 15 \mathrm{~km})$ and approximately coincides with the $20 \mathrm{~km}$ shown in Fig. 4. Thus, a reasonable explanation is that the initial GW with $\lambda_{z}=15 \mathrm{~km}$ is vanishingly small in the region of $80-140 \mathrm{~km}$. Then as the simulation progresses and the wave propagates up, the initial vanishingly small GW with $\lambda_{z}=15 \mathrm{~km}$ in the region of $80-140 \mathrm{~km}$ is replaced by the refracted GW with $\lambda_{z}=20 \mathrm{~km}$ that had propagated from below. Here, the refracted GW with $\lambda_{z}=20 \mathrm{~km}$ is likely caused by the dispersion/refraction of the wave packet propagating in the non-isothermal atmosphere.

As the mean wind acceleration becomes more prominent after $180 \mathrm{~min}, \lambda_{z}$ decreases to $5.5 \mathrm{~km}$ (Fig. 4) until the end of our simulation. Figure 3 shows that the intrinsic frequency is $2.6 \times 10^{-3} \mathrm{~s}^{-1}$ (calculated from the apparent wave period of $32 \mathrm{~min}$ and the mean wind of $20 \mathrm{~m} \mathrm{~s}^{-1}$ shown in Fig. 3) at $150 \mathrm{~min}$. Then at $300 \mathrm{~min}$, the intrinsic frequency is $7.2 \times$ $10^{-4} \mathrm{~s}^{-1}$ (calculated from the apparent period of $23 \mathrm{~min}$ and the mean wind of $120 \mathrm{~m} \mathrm{~s}^{-1}$ at this time). Thus, the decrease of $\lambda_{z}$ from $20 \mathrm{~km}$ at $\sim 150 \mathrm{~min}$ to $5.5 \mathrm{~km}$ at $300 \mathrm{~min}$ satisfies Eq. (7) since $N$ is almost constant at the same altitude. Therefore, the variation of $\lambda_{z}$ in Fig. 4 is caused by the combining effects of dispersion/refraction (before $\sim 150 \mathrm{~min}$ ) and mean flow acceleration (after $\sim 150 \mathrm{~min}$ ).

It has been suggested that the observed large wind shears may be the result of the superposition of various waves (GWs, tides, etc.) and the mean flow (Larsen, 2002; Zhao et al., 2003; Fritts et al., 2004; Yue et al., 2010). The individual contributions to the total wind shear from the mean wind shear (Fig. 5a) and the perturbation wind shear (Fig. 5b) for the case EM are shown in Fig. 5. Here, the mean wind shear 


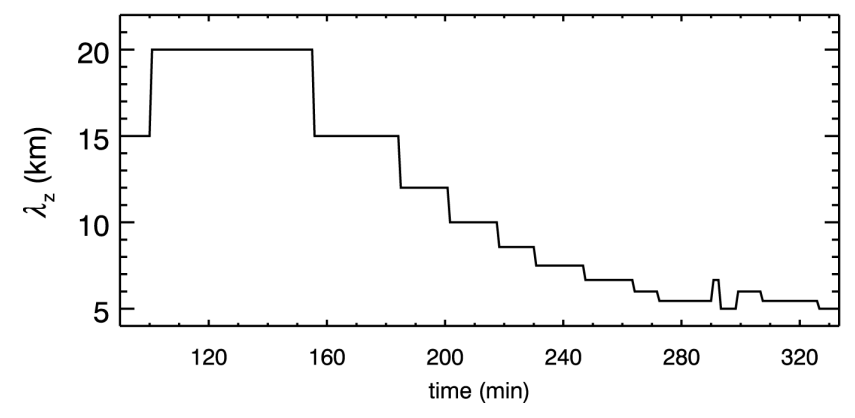

Figure 4. Temporal evolution of the vertical wavelength for the case EM.

is calculated as the vertical gradient of the mean wind, and the perturbation wind shear is calculated as the vertical gradient of the perturbation wind and is equivalent to the total wind shear minus the mean wind shear. Figure 5 shows that the perturbation wind shear is larger than the mean wind shear by one order of magnitude. This is in contrast to the significant contribution of GW-mean-wind interaction to the mean wind (Fig. 2b). Although the direct contribution of the mean wind to the total shear is relatively small, the accelerated mean wind reduces the intrinsic frequency and the vertical wavelength of GWs (Fig. 4) due to self-acceleration, which in turn results in a large wind shear. Therefore, the accelerated mean wind caused by the GW's momentum deposition plays an indirect role in forming large wind shears.

\section{Comparative studies}

\subsection{Effects of GW scales on the formation of large winds and wind shears}

GWs have a broad spectrum of horizontal and vertical wavelengths in the lower atmosphere (Fritts and Alexander, 2003). Thus, the scales of initial GWs may influence the formation of large winds and wind shears in the MLT region. To illustrate this effect, the total wind, mean wind, perturbation wind, and the total wind shear for the cases of EL (long waves) and ES (short waves) are shown in Figs. 6 and 7, respectively. By comparing the results from the three cases with different wave scales in Figs. 2, 6, and 7, it is clear that the maximum of total winds and mean winds increase with the scales of GWs. For large-scale GWs, the total winds can be as large as $\sim 210 \mathrm{~m} \mathrm{~s}^{-1}$ between 100 and $120 \mathrm{~km}$; for small-scale GWs, the total winds can exceed $100 \mathrm{~m} \mathrm{~s}^{-1}$. This is because the GW with the longer vertical wavelength and the larger apparent horizontal phase velocity will achieve larger amplitude before reaching convective and dynamic instability (Lindzen, 1981). According to Lindzen (1981), the acceleration rate caused by the wave breaking is proportional to the cube of the intrinsic phase velocity, which is dependent on the apparent horizontal phase velocity and the mean wind.
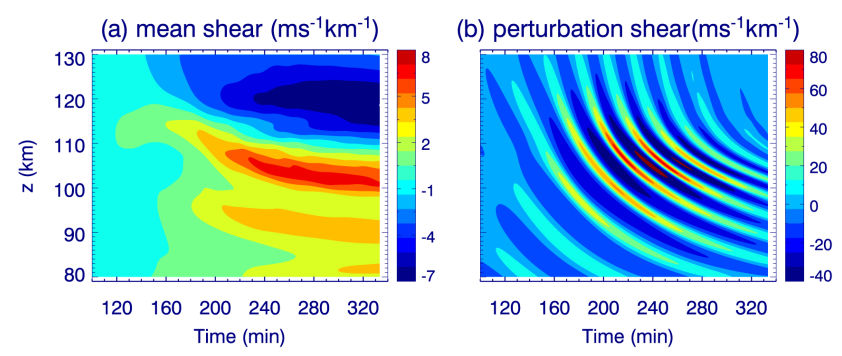

Figure 5. Time-height contours of (a) mean wind shear and (b) perturbation wind shear located at the midpoint of the horizontal computation domain for the case EM.

Thus, for the large-scale wave, its momentum flux and divergence associated with wave breaking, along with the wave induced mean wind, are larger given the same initial wave amplitude.

Although the induced total winds and mean winds increase with GW scales, the numerical experiments show that the maxima of total wind shears do not increase significantly with GW scales. The maxima of wind shears are about 72 , 82, and $76 \mathrm{~m} \mathrm{~s}^{-1} \mathrm{~km}^{-1}$ in EL, EM, and ES, respectively. The peak of wind shears appears at approximately the same heights $(100-120 \mathrm{~km})$ for these cases. The perturbation wind shear is determined by both the wind perturbation amplitude and the vertical wavelength of the GW. Although the total wind in EL reaches larger values, its maximum shear is offset by its longer vertical wavelength.

The waves in the cases presented here are all relatively fast GWs. Their apparent horizontal phase velocities are 30.2, 45.1 , and $59.4 \mathrm{~m} \mathrm{~s}^{-1}$, respectively. This is because only fast waves can penetrate into the MLT altitudes without being filtered by the background wind (Fritts and Vadas, 2008). Additional simulation is performed for an initial GW source with slower horizontal phase velocity (not shown here). Because the slower wave has slower apparent horizontal phase velocity and thus intrinsic horizontal phase velocity, weaker mean wind acceleration is induced. In addition, the GW with slower horizontal phase velocity achieves smaller amplitude before reaching convective and dynamic instability (Lindzen, 1981). Therefore, the mean wind and wind shear driven by the slower wave is weaker than those driven by the faster waves.

\subsection{Effects of different background temperature}

The background temperature determines the buoyancy frequency $N$ (the red lines in Fig. 1) and the atmospheric static stability. This, in turn, influences the characteristics, stability, and momentum deposition of GWs, as well as the mean wind acceleration driven by GW dissipation and breaking. To examine the influences of background temperature on the formation of large winds and wind shears, we show the temporal evolution of the peak speed and peak height (where the 
(a) total wind $\left(\mathrm{ms}^{-1}\right)$

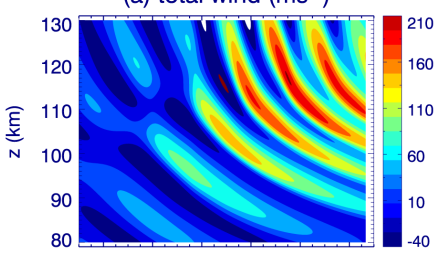

(c) perturbation wind $\left(\mathrm{ms}^{-1}\right)$

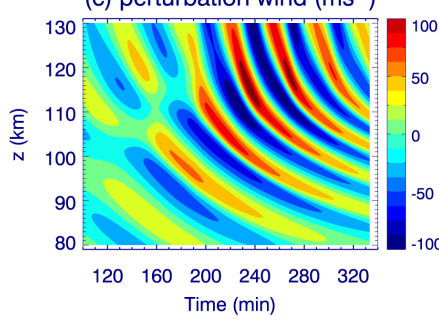

(b) mean wind $\left(\mathrm{ms}^{-1}\right)$

(d) total wind shear $\left(\mathrm{ms}^{-1} \mathrm{~km}^{-1}\right)$

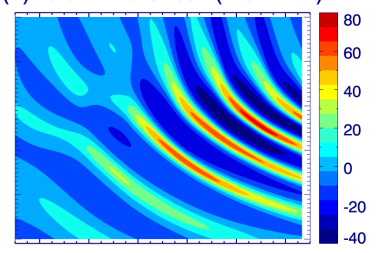
Time (min)

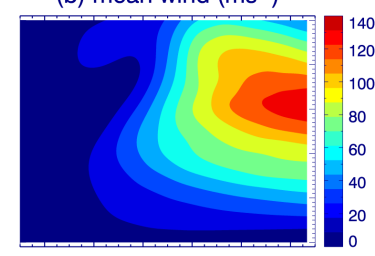

$120 \quad 160 \quad 200 \quad 240 \quad 280 \quad 320$

Figure 6. Same as Fig. 2, but for the case EL (GW with $\lambda_{z}=$ $20 \mathrm{~km})$. (c) perturbation wind $\left(\mathrm{ms}^{-1}\right)$

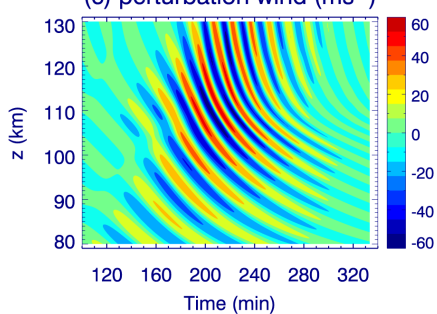

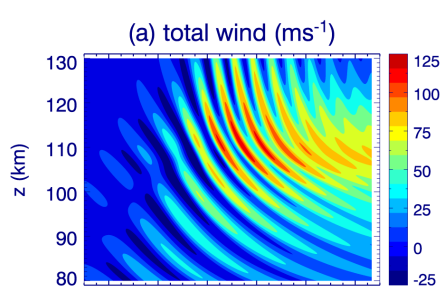

(b) mean wind $\left(\mathrm{ms}^{-1}\right)$

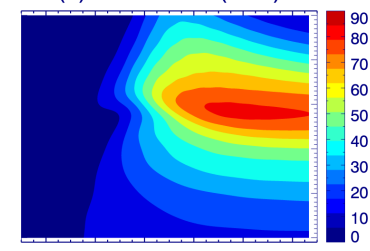

(d) total wind shear $\left(\mathrm{ms}^{-1} \mathrm{~km}^{-1}\right)$

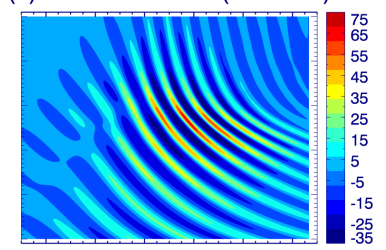

$\begin{array}{llllll}120 & 160 & 200 & 240 & 280 & 320\end{array}$ Time (min)
Figure 7. Same as Fig. 2, but for the case ES (GW with $\lambda_{z}=$ $10 \mathrm{~km})$.

peak speed occurs) of the mean wind and total wind shear for the cases of $\mathrm{NM}$ (the solid line, $70^{\circ} \mathrm{N}$ ) and $\mathrm{SM}$ (the dash line, $70^{\circ} \mathrm{S}$ ) in Fig. 8. Although the main features, such as the magnitudes and the peak heights of the mean wind and wind shear, are similar, there are some differences between the two cases. First, the mean wind is accelerated relatively earlier in the NM. Consequently, the maximum wind shear appears earlier in the NM. Second, the heights of the mean wind peaks are slightly higher in the NM than that in the SM.

The reason for the above differences can be understood qualitatively from the temperature dependency of vertical group velocity, $c_{g z}$, which is based on the linear theory,

$c_{g z}=\Omega /\left|k_{z}\right|$.

According to $\left|k_{z}\right|=N k_{x} /|\Omega|$ (Eq. 33 of Fritts and Alexander, 2003), $k_{z}$ is proportional to $N$. Thus, $c_{g z}$ is inversely
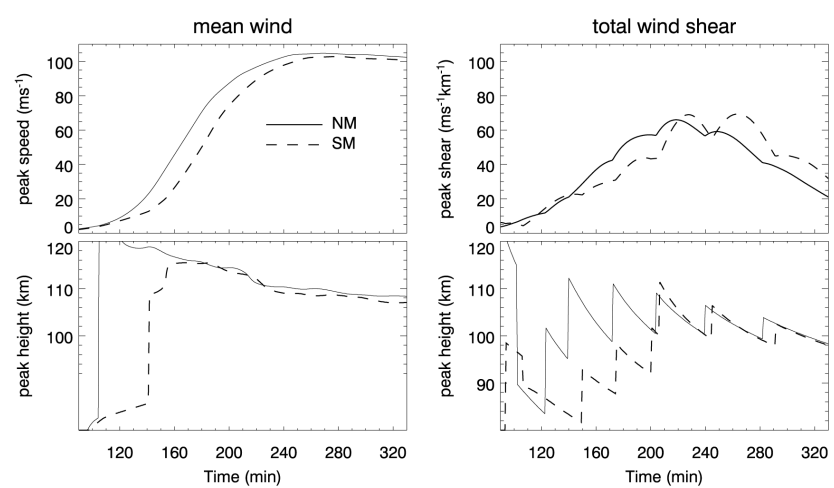

Figure 8. Temporal evolution of the peak speed (upper two panels) and peak height (lower two panels) of mean wind (left two panels) and total wind shear (right two panels) for the cases NM (the solid lines) and SM (the dash lines).

proportional to $N$ given the same $\Omega$ for the same GW source. From the profiles of $N$ shown in Fig. 1, we can find that $N$ is larger at $70^{\circ} \mathrm{S}$ than at $70^{\circ} \mathrm{N}$ above $80 \mathrm{~km}$ because the mesopause is higher in winter than in summer ( $\mathrm{Xu}$ et al., 2007). So the GW is faster in the NM than that in the SM. Thus, the wind acceleration, the height of peak winds, and wind shears occur earlier at $70^{\circ} \mathrm{N}$ than at $70^{\circ} \mathrm{S}$.

Only a few quasi-monochromatic GWs are studied in this work to demonstrate that the large winds and wind shears can be formed through interactions between GWs and mean wind. A statistical study, with a full spectrum of GWs launched in the 2-D model, is essential to reveal a more comprehensive picture of the dependence of large winds and wind shears on the background temperature.

\section{Conclusions}

Using a fully nonlinear 2-D numerical model, which includes a proper eddy diffusion coefficient of $100 \mathrm{~m}^{2} \mathrm{~s}^{-1}$ and standard molecular diffusion, we simulated the GW breaking in a non-isothermal compressible atmosphere, and their contributions to the formation of large winds and wind shears in the MLT region.

The mechanism responsible for the formation of large winds and wind shears through nonlinear interactions between breaking GWs and mean wind can be summarized as follows. First, the breaking and dissipating GWs and their momentum deposition induce dramatic mean wind acceleration. Second, the accelerated mean wind reduces the vertical wavelengths of GWs due to the decrease of intrinsic GW frequency. Third, both the accelerated mean winds and the reduced vertical wavelengths of GWs contribute to the enhancement of wind shears. This, in turn, creates a condition that favors the occurrence of GW breaking and momentum deposition, as well as mean wind acceleration. Enhanced mean wind further reduces the vertical wavelength 
and induces larger wind shears. The whole process is positive feedback among GWs momentum deposition, mean wind acceleration, decreasing vertical wavelength, wind shear enhancement, and instability.

Our comparative studies show that the momentum deposited by the breaking of larger (smaller) scale GWs having longer (shorter) vertical wavelength, associated with larger (smaller) intrinsic horizontal phase speed, will result in larger (smaller) winds but will not result in larger (smaller) wind shears. The main contribution to the total wind shear comes from the wave perturbation and, to a lesser degree, from the mean flow acceleration caused by the wave breaking. However, the accelerated mean wind in the GW horizontal propagation direction results in the decrease of the vertical wavelength and a further increase the perturbation wind shear in the MLT region.

Background temperature and the static stability (measured by the buoyancy frequency $N$ ) affect the time and height of mean wind acceleration. This is because different background temperatures result in different wave group velocities. These affect the time of GW breaking and mean wind acceleration. However, the large winds and wind shears can be formed in various temperature backgrounds.

It should be noted that GW breaking and its nonlinear interactions with the mean wind are capable of inducing large winds and wind shears in the MLT region. Other possible mechanisms, such as interactions among GWs, tides, planetary waves, and background winds, magnetized Rossby waves (Kelley et al., 2009) could contribute to the formation of large winds and wind shears.

Acknowledgements. This work was supported by the Chinese Academy of Sciences (KZZD-EW-01-2), the National Natural Science Foundation of China (41374158, 41229001, and 41331069) and the National Important basic Research Project of China (2011CB811405). This work was also supported by the Specialized Research Fund and the Open Research Program of the State Key Laboratory of Space Weather. The National Center for Atmospheric Research is sponsored by the National Science Foundation. The computations were performed by Numerical Forecast Modeling R\&D and VR System of State Key Laboratory of Space Weather and Special HPC work stand of Chinese Meridian Project.

Topical Editor M. Kosro thanks two anonymous referees for their help in evaluating this paper.

\section{References}

Andreassen, Ø., Wasberg, C.-E., Fritts, D. C., and Isler, J. R.: Gravity wave breaking in two and three dimensions. 1: Model description and comparison of two-dimensional evolutions, J. Geophys. Res., 99, 8095-8108, doi:10.1029/93JD03435, 1994.

Andreassen, Ø., Hvidsten, P. Ø., Fritts, D. C., and Arendt, S.: Vorticity dynamics in a breaking gravity wave. 1: Initial instability evolution, J. Fluid Mech., 367, 27-46, doi:10.1017/S0022112098001645, 1998.
Banks, P. M. and Kockarts, G.: Aeronomy, Part B, 355 pp., Elsevier, New York, 1973.

Clemesha, B. R.: Sporadic neutral metal layers in the mesosphere and lower thermosphere, J. Atmos. Terr. Phys., 57, 725-736, doi:10.1016/0021-9169(94)00049-T, 1995.

Fritts, D. C. and Alexander, M. J.: Gravity wave dynamics and effects in the middle atmosphere, Rev. Geophys., 41, 1003, doi:10.1029/2001RG000106, 2003.

Fritts, D. C. and Dunkerton, T. J.: A quasi-linear study of gravitywave saturation and self-acceleration, J. Atmos. Sci., 41, 32723289, 1984.

Fritts, D. C. and Lund, T. S.: Gravity wave influences in the thermosphere and ionosphere: Observations and recent modeling, in Aeronomy of the Earth's Atmosphere and Ionosphere, edited by: Abdu, M. A., Pancheva, D., and Bhattacharyya, A., 109-130, Springer, doi:10.1007/978-94-007-0326-1_8, 2011.

Fritts, D. C. and Vadas, S. L.: Gravity wave penetration into the thermosphere: sensitivity to solar cycle variations and mean winds, Ann. Geophys., 26, 3841-3861, doi:10.5194/angeo-263841-2008, 2008.

Fritts, D. C., Isler, J. R., Andreassen, Ø.: Gravity wave breaking in two and three dimensions, 2, Threedimensional evolution and instability structure, J. Geophys. Res., 99, 8109-8123, 1994

Fritts, D. C., Palmer, T. L., Andreassen, Ø., and Lie, I.: Evolution and breakdown of Kelvin-Helmholtz billows in stratified compressible flows: I. Comparison of two- and three-dimensional flows, J. Atmos. Sci., 53, 3173-3191, 1996.

Fritts, D. C., Arendt, S., and Andreassen, Ø.: Vorticity dynamics in a breaking internal gravity wave Whitehead. 2: Vortex interactions and transition to turbulence, J. Fluid Mech., 367, 47-65, doi:10.1017/S0022112098001633, 1998.

Fritts, D. C., Williams, B. P., She, C. Y., Vance, J. D., Rapp, M., Lübken, F. -J., Müllemann, A., Schmidlin, F. J., and Goldberg, R. A.: Observations of extreme temperature and wind gradients near the summer mesopause during the MaCWAVE/MIDAS rocket campaign, Geophys. Res. Lett., 31, L24S06, doi:10.1029/2003GL019389, 2004.

Fritts, D. C., Wang, L., Werne, J., Lund, T., and Wan, K.: Gravity wave instability dynamics at high Reynolds numbers, 1 :Wave field evolution at large amplitudes and high frequencies, J. Atmos. Sci., 66, 1126-1148, doi:10.1175/2008JAS2726.1, 2009a.

Fritts, D. C., Wang, L., Werne, J., Lund, T., and Wan, K.: Gravity wave instability dynamics at high Reynolds numbers: 2 . Turbulence evolution, structure, and anisotropy, J. Atmos. Sci., 66, 1149-1171, doi:10.1175/2008JAS2727.1, 2009b.

Fukao, S., Yamanaka, M. D., Ao, N., Hocking, W. K., Sato, T., Yamamoto, M., Tsuda, T., and Kato, S.: Seasonal variability of vertical eddy diffusivity in the middle atmosphere: 1 . Three-year observations by the middle and upper atmosphere radar, J. Geophys. Res., 99, 18973-18987, 1994.

Hecht, J. H.: Instability layers and airglow imaging, Rev. Geophys., 42, RG1001, doi:10.1029/2003RG000131, 2004.

Hocking, W. K.: Turbulence in the region $80-120 \mathrm{~km}$, Adv. Space Res., 7, 171-181, 1987.

Hu, X., Liu, A. Z., Gardner, C. S., and Swenson, G. R.: Characteristics of quasi-monochromatic gravity waves observed with $\mathrm{Na}$ lidar in the mesopause region at Starfire Optical Range, NM, Geophys. Res. Lett., 29, 2169, doi:10.1029/2002GL014975, 2002. 
Kelley, M. C., Seyler, C. E., and Larsen, M. F.: Two-dimensional turbulence, space shuttle plume transport in the thermosphere, and a possible relation to the Great Siberian Impact Event, Geophys. Res. Lett., 36, L14103, doi:10.1029/2009GL038362, 2009.

Keneshea, T. J., Zimmerman, S. P., and Philbrick, C. R.: A dynamic model of the mesosphere and lower thermosphere, Planet. Space Sci., 27, 385-401, 1979.

Koizumi, Y., Kubota, M., Murayama, Y., Abo, M., Uchiumi, M., Igarashi, K., Iwagami, N., Abe, T., and Oyama, K.-I.: In situ observations of instabilities in the mesopause region using foil chaff technique during the Waves in Airglow Structures Experiment (WAVE) campaigns, J. Geophys. Res., 114, D20114, doi:10.1029/2009JD012237, 2009.

Kubota, M., Kawamura, S., Abo, M., Koizumi, Y., Murayama, Y., Yamamori, M., Shiokawa, K., Otsuka, Y., Uchiumi, M., Igarashi, K., Abe, T. Oyama, K., and Iwagami, N.: A fastpropagating, large-scale atmospheric gravity wave observed in the WAVE2004 campaign, J. Geophys. Res., 111, D21110, doi:10.1029/2005JD006788, 2006.

Larsen, M. F.: Coqui 2: Mesospheric and lower thermospheric wind observations over Puerto Rico, Geophys. Res. Lett., 27, 445-448, doi:10.1029/1999GL010704, 2000.

Larsen, M. F.: Winds and shears in the mesosphere and lower thermosphere: Results from four decades of chemical release wind measurements, J. Geophys. Res., 107, 1215, doi:10.1029/2001JA000218, 2002.

Larsen, M. F. and Fesen, C. G.: Accuracy issues of the existing thermospheric wind models: can we rely on them in seeking solutions to wind-driven problems?, Ann. Geophys., 27, 2277-2284, doi:10.5194/angeo-27-2277-2009, 2009.

Larsen, M. F., Liu, A. Z., Bishop, R. L., and Hecht, J. H.: TOMEX: A comparison of lidar and sounding rocket chemical tracer wind measurements, Geophys. Res. Lett., 30, 1375, doi:10.1029/2002GL015678, 2003.

Larsen, M. F., Liu, A. Z., Gardner, C. S., Kelley, M. C., Collins, S., Friedman, J., and Hecht, J. H.: Observations of overturning in the upper mesosphere and lower thermosphere, J. Geophys. Res., 109, D02S04, doi:10.1029/2002JD003067, 2004.

Larsen, M. F., Yamamoto, M., Fukao, S., Tsunoda, R. T., and Saito, A.: Observations of neutral winds, wind shears, and wave structure during a sporadic-E/QP event, Ann. Geophys., 23, 23692375, doi:10.5194/angeo-23-2369-2005, 2005.

Li, F., Liu, A. Z., and Swenson, G. R.: Characteristics of instabilities in the mesopause region over Maui, Hawaii, J. Geophys. Res., 110, D09S12, doi:10.1029/2004JD005097, 2005.

Li, T., She, C.-Y., Liu, H.-L., Yue, J., Nakamura, T., Krueger, D. A., Wu, Q., Dou, X., and Wang, S.: Observation of local tidal variability and instability, along with dissipation of diurnal tidal harmonics in the mesopause region over Fort Collins, Colorado $\left(41^{\circ} \mathrm{N}, 105^{\circ} \mathrm{W}\right)$, J. Geophys. Res., 114, D06106, doi:10.1029/2008JD011089, 2009.

Lindzen, R. S.: Turbulence and stress due to gravity waves and tidal breakdown, J. Geophys. Res., 86, 9707-9714, doi:10.1029/JC086iC10p09707, 1981.

Liu, H.-L.: On the large wind shear and fast meridional transport above the mesopause, Geophys. Res. Lett., 34, L08815, doi:10.1029/2006GL028789, 2007.
Liu, H.-L., Hays, P. B., and Roble, R. G.: A numerical study of gravity wave breaking and impacts on turbulence and mean state, J. Atmos. Sci., 56, 2152-2177, 1999.

Liu, X., Xu, J., Liu, H., and Ma, R.: Nonlinear interactions between gravity waves with different wavelengths and diurnal tide, J. Geophys. Res., 113, D08112, doi:10.1029/2007JD009136, 2008.

Liu, X., Xu, J., Gao, H., and Chen, G.: Kelvin-Helmholtz billows and their effects on mean state during gravity wave propagation, Ann. Geophys., 27, 2789-2798, doi:10.5194/angeo-272789-2009, 2009.

Liu, X., Xu, J., Yue, J., and Vadas, S. L.: Numerical modeling study of the momentum deposition of small amplitude gravity waves in the thermosphere, Ann. Geophys., 31, 1-14, doi:10.5194/angeo31-1-2013, 2013.

Lu, X., Liu, A. Z., Swenson, G. R., Li, T., Leblanc, T., and McDermid, I. S.: Gravity wave propagation and dissipation from the stratosphere to the lower thermosphere, J. Geophys. Res., 114, D11101, doi:10.1029/2008JD010112, 2009.

Lund, T. S. and Fritts, D. C.: Numerical simulation of gravity wave breaking in the lower thermosphere, J. Geophys. Res., 117, D21105, doi:10.1029/2012JD017536, 2012.

Manson, A. H. and Meek, C. E.: Gravity wave propagation characteristics $(60-120 \mathrm{~km})$ as determined by the Saskatoon MF Radar (Gravnet) System: $1983-85$ at 52 ${ }^{\circ}$ N, $107^{\circ}$ W, J. Atmos. Sci., 45, 932-946, 1988.

Miyagawa, H., Nakamura, T., Tsuda, T., Abo, M., Nagasawa, C., Kawahara, T. D., Kobayashi, K., Kitahara, T., and Nomura, A.: Observations of mesospheric sporadic sodium layers with the MU radar and sodium lidars, Earth Planet Sci., 51, 785-797, 1999.

Nakamura, T., Tsuda, T., Yamamoto, M., Fukao, S., and Kato, S.: Characteristics of gravity waves in the mesosphere observed with the MU radar: 2. Propagation direction, J. Geophys. Res., 98, 8911-8923, doi:10.1029/92JD03030, 1993.

Oppenheim, M. M., Sugar, G., Slowey, N. O., Bass, E., Chau, J. L., and Close, S.: Remote sensing lower thermosphere wind profiles using non-specular meteor echoes, Geophys. Res. Lett., 36, L09817, doi:10.1029/2009GL037353, 2009.

Oppenheim, M. M., Arredondo, S., and Sugar, G.: Intense Winds and Shears in the Equatorial Lower Thermosphere Measured by High Resolution Non-Specular Meteor Radar, J. Geophys. Res. Space Phys., 119, 2178-2186, doi:10.1002/2013JA019272, 2014.

Phibrick, C. R., Barnett, J., Gerndt, R., Offerman, D., Pendlteton Jr, W. R., Schlyter, P., Witt, G., and Schmidlin, J. F.: Temperature measurements during the CAMP program, Adv. Space. Res., 4, 153-156, doi:10.1016/0273-1177(84)90278-3, 1984.

Picone, J. M., Hedin, A. E., Drob, D. P., and Aikin, A. C.: NRLMSISE-00 empirical model of the atmosphere: Statistical comparisons and scientific issues, J. Geophys. Res., 107, 1468, doi:10.1029/2002JA009430, 2002.

Qian, J., Gu, Y., and Gardner, C. S.: Characteristics of the sporadic $\mathrm{Na}$ layers observed during the Airborne Lidar and $\mathrm{Ob}-$ servations of Hawaiian Airglow/Airborne Noctilucent Cloud (ALOHA/ANLC-93) campaigns, J. Geophys. Res., 103, 63336347, doi:10.1029/97JD03374, 1998.

She, C.-Y.: Initial full-diurnal-cycle mesopause region lidar observations: diurnal-means and tidal perturbations of temperature and 
winds over Fort Collins, CO $\left(41^{\circ} \mathrm{N}, 105^{\circ} \mathrm{W}\right)$, J. Atmos. Sol. Terr. Phys., 66, 663-674, doi:10.1016/j.jastp.2004.01.037, 2004. Snively, J. B., Pasko, V. P., Taylor, M. J., and Hocking, W. K.: Doppler ducting of short-period gravity waves by midlatitude tidal wind structure, J. Geophys. Res., 112, A03304, doi:10.1029/2006JA011895, 2007.

Vadas, S. L. and Fritts, D. C.: Thermospheric responses to gravity waves: Influences of increasing viscosity and thermal diffusivity, J. Geophys. Res., 110, D15103, doi:10.1029/2004JD005574, 2005.

VanZandt, T. E. and Fritts, D. C.: A theory of enhanced saturation of the gravity wave spectrum due to increases in atmospheric stability, Pure Appl. Geophys., 130, 399-420, doi:10.1007/BF00874466, 1989.

Walterscheid, R. L. and Schubert, G.: Nonlinear evolution of an upward propagation gravity wave: Overturning, convection, transience and turbulence, J. Atmos. Sci., 47, 101-125, 1990.

Weinstock, J.: The turbulence field generated by a linear gravity wave, J. Atmos. Sci., 44, 410-420, 1987.

Weinstock, J.: Superadiabatic excess and gravity wave saturation, J. Atmos. Sci., 45, 3519-3520, 1988.

Whitehead, J. D.: Production and prediction of sporadic E, Rev. Geophys., 8, 65-144, doi:10.1029/RG008i001p00065, 1970.

Wu, Y. -F. and Widdel, H.-U.: Saturated Gravity Wave Spectrum in the Polar Summer Lower Thermosphere Observed by Foil Chaff during Campaign "Sodium 88”, J. Atmos. Sci., 49, 1781-1789, 1992.

Xu, J., Smith A. K., and Ma, R.: A numerical study of the effect of gravity-wave propagation on minor species distributions in the mesopause region, J. Geophys. Res., 108, 4119, doi:10.1029/2001JD001570, 2003.
Xu, J., Liu, H.-L., Yuan, W., Smith, A. K., Roble, R. G., Mertens, C. J., Russell III, J. M., and Mlynczak, M. G.: Mesopause structure from Thermosphere, Ionosphere, Mesosphere, Energetics, and Dynamics (TIMED)/Sounding of the Atmosphere Using Broadband Emission Radiometry (SABER) observations, J. Geophys. Res., 112, D09102, doi:10.1029/2006JD007711, 2007.

Xu, J., Smith A. K., Liu, H.-L., Yuan, W., Wu, Q., Jiang, G., Mlynczak, M. G., Russell III, J. M., and Franke, S. J.: Seasonal and quasi-biennial variations in the migrating diurnal tide observed by Thermosphere, Ionosphere, Mesosphere, Energetics and Dynamics (TIMED), J. Geophys. Res., 114, D13107, doi:10.1029/2008JD011298, 2009.

Yue, J. and Liu, H.-L.: Fast meridional transport in the lower thermosphere by large-scale waves, J. Atmos. Sol. Terr. Phys., 72, 1372-1378, doi:10.1016/j.jastp.2010.10.001, 2010.

Yue, J., She, C.-Y., and Liu, H.-L.: Large wind shears and stabilities in the mesopause region observed by $\mathrm{Na}$ lidar at midlatitude, J. Geophys. Res., 115, A10307, doi:10.1029/2009JA014864, 2010.

Yue, J., Liu, H.-L., Meier, R. R., Chang. L., Gu, S. Y., and Russell III, J.: On the fast zonal transport of the STS-121 space shuttle exhaust plume in the lower thermosphere, J. Atmos. Sol. Terr. Phys., 94, 19-27, 2013.

Zhao, Y., Liu, A. Z., and Gardner, C. S.: Measurements of atmospheric stability in the mesopause region at Starfire Optical Range, NM, J. Atmos. Sol. Terr. Phys., 65, 219-232, doi:10.1016/S1364-6826(02)00288-2, 2003. 